Original Research

\title{
The Validity and Reliability of Quality of Nursing Work Life Instrument for Hospital Nurses
}

\section{Utami Utami ${ }^{1,4}$, Hari Kusnanto², Bagus Riyono ${ }^{3}$ and Syahirul Alim²}

1 Doctoral Candidate of Public Health Programme, Faculty of Medicine, Public Health and Nursing, Universitas Gadjah Mada, Yogyakarta, Indonesia

2 Faculty of Medicine, Public Health and Nursing, Universitas Gadjah Mada, Yogyakarta, Indonesia

${ }^{3}$ Faculty of Psychology, Universitas Gadjah Mada, Yogyakarta, Indonesia

${ }^{4}$ Department of Nursing, STIKES ABI Surabaya, East Java, Indonesia

\section{ABSTRACT}

Introduction: The validity and reliability of the quality of nursing work life (QNWL) instrument in hospitals that suitable to treatment needs include: trust, care, respect, learn, and contribute need, have to be assessed. Therefore, in order to perform good care, it is necessary to notice QNWL aspect, which the implementation may be assessed by using valid and reliable instruments. This study aimed to evaluate the construct validity of the QNWL scale in hospital.

Methods: The research used a cross-sectional approach and the respondents were 100 experts in nursing and 400 nurses working in four hospitals in Gresik, Indonesia, who have been working for minimum one year. The sampling technique was purposive sampling. We analyzed the data using content analysis, the validity of item discrimination using Pearson products moment, reliability with Cronbach's alpha, and construct validity with Confirmatory Factor Analysis.

Results: The results based on content validity index QNWL instrument was $0.2075-0.915$, with an average 0.7059 (high). Item discrimination capacity was $0.339-0.79$ (high), while the reliability was 0.9374 (very high) and the validity of the construct meets the goodness of fit criteria.

Conclusion: All constructs are able to explain and support the QNWL instrument model. This research can be used to measure the quality of work life of nurses in all classes of hospitals in Indonesia.

\section{ARTICLE HISTORY}

Received: November 14, 2018

Accepted: January 09, 2019

\section{KEYWORDS}

Validity; reliability;

quality of nursing work life; instrument; hospital

\section{CONTACT}

\section{Utami Utami}

$\triangle$ tami_ola@yahoo.com

$\triangleq$ Doctoral Candidate of Public Health Programme, Faculty of Medicine, Public Health and Nursing, Universitas Gadjah Mada, Yogyakarta, Indonesia

Cite this as: Utami, U., Kusnanto., H., Riyono, B., \& Alim, S. (2018). The Validity and Reliability of Quality of Nursing Work Life Instrument for Hospital Nurses. Jurnal Ners, 13(2), 227-232. doi:http://dx.doi.org/10.20473/in.v13i2.10450

\section{INTRODUCTION}

Quality of nursing work life (QNWL) is described as strength as well as motivating and increasing employee productivity at work environment in the organization. Quality of nursing work life is a sustainable management approach directed for improving the quality of work, (Hamim Nur, et al, 2015). Quality of Nursing Work Life (QNWL) serves as a predictor of a nurse's intent to leave and a hospital nurse turnover, Since QNWL can be influenced by various factors, scholars and organizations have serious attention on how to scientifically assess the work conditions and mental statuses of nurses, (Fu et al., 2015). QNWL is needed in the work environment at the hospital.

Through human resource management approach, the hospital must be able to create QNWL that can provide opportunities for self-development, which are welfare covering workers' basic needs as well as a safe and comfortable work environment, in order to generate work morale as an effort to achieve goals 
better. Quality means the ability to produce goods or services, marketed and to provide services constantly based on costumers' needs. That way, the goods or services produced are able to compete and to succeed in seizing the market. QNWL instrument is basically looking for ways to improve the quality of life and to create better work results or to achieve high performance (Kheradman, E, et al).

However, QNWL measurement tools that have been validated for the implementation in Indonesia have not been sufficient yet. Past research indicates that Quality Work Life is negatively associated with job stress (Mosadeghrad, et al 2011; Bragard, et al, 2012), turnover intention (Mosadeghrad et al., 2011 and Almalki, et al, 2012), and depression symptoms (Wang, 2009), and positively related to productivity (Nayeri, et al, 2011) and patient safety (Mitchell JI, 2012).

Quality of nursing work life is a management approach that is continuously directed for improving the quality of work. Thus, hospital management should care about the condition of its nurses in order to increase their loyalty to give better service which will ultimately improve employee performance. Overall, the best quality of care provided by the nurse is influenced by QNWL, which is an important element in health care services, (Clarke \& Brooks, 2010). The preliminary study found that the number of nurses was around $60 \%$ of the total hospital employees. In terms of intensity of interaction with patients, the nurse is also an element of human resources with the highest intensity of interaction with the patient. Therefore, the quality of nursing work life (QNWL) instrument, especially in a hospital, need to be prepared based on the nurses' needs of QNWL.

It aims to achieve an effective work environment that brings the needs and values of the organization to the employee's personal need and value. QNWL also emphasizes the feeling perceived from the interaction between individual and work environment (Mohamad M and Mohamed W.N, 2012). Effective and efficient services can be measured based on two aspects, namely the service process aspect and service output aspect. In the process aspect, the parameter can be known from the service process in general (for example, the service of the implementation and documentation of nursing care). If the service process aspect in a hospital is not good, it will result in low service performance (for example, a low Bed Occupancy Ratio and incomplete filling of care document) (Soejadi, 2010).

Research related to QNWL is important to determine the quality of nursing work life in every hospital. Each hospital has different organizational systems and environments, so QNWL for their employee is different as well. This difference can be related to the state of the unit, the number and type of units, policies, and the environment in each unit (Nursalam, et al, 2018). A better understanding of QNWL is fundamental to specific strategies to improve QNWL and organizational productivity.
The effectiveness of specific strategies, including nurses' participation in making a decision, removing non-nursing tasks, and building healthy environments, could be evaluated using this instrument. The greater achievement of QNWL may increase nurses' job satisfaction and improve patient care as well as organizational productivity (Fu et al., 2015). Thus, it can be concluded that a valid and reliable quality of work life instrument can be used to assess organizational culture, which is oriented to a balance between productivity and employee welfare. In addition, welfare is defined as subjective wellbeing that has psychological dimensions such as trust, care, and mutual respect. Meanwhile, productivity also includes attitude and behaviour that support the achievement of optimal work outcomes, namely the willingness to learn and the commitment to contribute. Accordingly, this study aims to evaluate the constructed validity of QNWL scale in a hospital.

\section{MATERIALS AND METHODS}

This study was a descriptive research study using a cross-sectional design. This research was conducted in five stages namely, first, preparing an initial draft of the instrument by determining the instrument's blueprint. Based on the blueprint, we compiled a statement in accordance with the type of instrument and the amount specified in the blueprint; second, getting an assessment from the experts who at least had educational background of a master or a professional experienced in the scale of design in the fields of public health, clinical nursing, clinical care to generate a revised version; third, revising the draft instrument; fourth, performing the first and the second stage of testing; and, five, compiling the final draft.

The number of respondents involved in this study was 100 experts in nursing, 50 nurses for the early stage of testing instrument, and 350 nurses for the final stages of the testing instrument. Inclusion criteria were nurses working in a public hospital for at least one year in Gresik, East Java, Indonesia, and nurses who agreed to participate in the present study and who were not on vacation. The adaptation of a scale into a different culture requires a group of at least 5-10 times greater than the number of scale items, (Bryne, 2009). The desired minimum sample size required was 175 participants based on 35 items. Without selecting a sample group for the study, the data was collected using questionnaires from a total of 350 nurses who agreed to participate in the study.

QNWL questionnaire was developed by Riyono (2012). Therefore, the QNWL measurement instrument to be developed can be aligned with Minnesota Satisfaction Questionnaire (MSQ) and Job Diagnostic Survey (JDS) as the standard organizational diagnostic tool, that became the parameters including psychological dimensions such as trust, care, respect, learn, and contribution. The sampling technique was purposive sampling. The QNWL developed by Riyono (2012) was to determine 
the quality of nursing work life. The scale consisted of 35 items and five subscales (trust, care, respect, learn, and contribution). Each item in the original scale was scored by a 5-point Likert scale ranging from "completely disagree (1 point)" and "completely agree (5 points)". The 35 items were reverse coded on the scale. The minimum total score was 35 and the maximum was 175 . Higher total score indicated better quality of work life.

This research had gone through a process of ethical feasibility research and had been approved by the Medical and Research Ethics Committee of Faculty of Medicine, Universitas Gadjah Mada number KE/FK /0168/EC/ 2017.

\section{RESULTS}

In the initial stage, there were 50 items in the QNWL instrument. The initial test aimed to determine the item discrimination power, face validity. This test involved 50 nurses as respondents. The content validity index (CVI) of the QNWL instrument was range from 0.2075 to 0.915 with an average score of 0.7059 (high) according to expert judgment based on the Aiken $\mathrm{V}$ formula validity score, (Aiken, 2014).

Based on Table 2, we found that $52 \%$ of items were very high, $18 \%$ criteria were high, $10 \%$ criteria were fair and $20 \%$ criteria were low, according to expert judgment. Item number $4,6,7,10,18,19,20$, $26,27,32,37,48,44,45$, and 46 Aiken $V$ formula validity scores less than 0.7 so that the items were considered invalid and not can be used again for measuring the QNWL indicator. After deducting the number of invalid statements, the number of items reduced to 35 statements. The item discrimination test results in the initial stage trial using Pearson product moment correlation obtained a validity score ( $r$ count) in the range $0.339-0.79$ for 50 instrument items, while the $r$ table was 0.279 , so that items with $r$ count were more the size of the $r$ table, which means this validity score was sufficient reason to state that this QNWL instrument was valid.

Test construct validity with factor analysis using the R program, the data included in the factor analysis were the five QNWL constructs containing 13 indicators and 35 item statements. Factor analysis involved 350 respondents who were nurses from four hospitals in Gresik Regency. Test construct validity with factor analysis using the R program, the data included in the factor analysis were five QNWL constructs containing 10 indicators and 35 item statements. Factor analysis involved 350 respondents who were nurses from four hospitals in Gresik Regency. Construct validity with loading factor of all indicators above 0.50, namely trust

Table 1 Initial draft and final results for the outline quality of nursing work life instrument

\begin{tabular}{|c|c|c|c|}
\hline \multirow{2}{*}{ Construct } & \multirow{2}{*}{ Indicator } & \multicolumn{2}{|c|}{ Number of Items } \\
\hline & & Initial draft & Final result \\
\hline $\begin{array}{l}\text { Trust } \\
20 \%\end{array}$ & $\begin{array}{l}\text { 1. Trust of supervisor to subordinates by willing to delegate tasks that are quite } \\
\text { risky to subordinates } \\
\text { 2. Share information about plans and problems in the organization } \\
\text { 3. Engaging subordinates in making important decisions }\end{array}$ & 10 & 7 \\
\hline Care & 4. Get involved in the organization in a responsible and caring manner & 10 & 8 \\
\hline $23 \%$ & $\begin{array}{l}\text { 5. Care for life dynamic of the organization } \\
\text { 6. Supervisor treat each subordinate as an individual and pay attention to their } \\
\text { needs, abilities, feelings, and aspirations }\end{array}$ & & \\
\hline Respect & 7. Improve nurse's ability & 10 & 6 \\
\hline $17 \%$ & $\begin{array}{l}\text { 8. Getting deeper knowledge about other people than just tolerance, admiration, } \\
\text { and interference with other individuals. }\end{array}$ & & \\
\hline Learn & 9. There is a passion and willingness to learn continuously for all nurses & 10 & 9 \\
\hline $26 \%$ & $\begin{array}{l}\text { 10. Develop new skills and competencies, } \\
\text { 11. Add new knowledge so that it will encourage the emergence of positive } \\
\text { attitudes in the organization. }\end{array}$ & & \\
\hline $\begin{array}{l}\text { Contribute } \\
14 \%\end{array}$ & $\begin{array}{l}\text { 12. Providing the widest opportunity for each employee to channel the source of } \\
\text { initiative and creativity in solving important problems faced by the } \\
\text { organization, in developing the organization, } \\
\text { 13. Make the climate pleasant for the organization. }\end{array}$ & 10 & 5 \\
\hline & TOTAL & 50 & 35 \\
\hline
\end{tabular}

Table 2 The result of expert judgment based on content validity criteria

\begin{tabular}{llc}
\hline \multicolumn{1}{c}{ Validity Criteria } & \multicolumn{1}{c}{ Item's Number } & Number of Items \\
\hline Very high $(0.80<\mathrm{V} 001.00)$ & $1,2,3,5,8,9,14,15,21,23,24,25,28,29,30,31,33,35,38$, & 26 \\
High $(0.60<\mathrm{V} \leq 0.80)$ & $39,41,42,43,47,49,50$ & 9 \\
Fair $(0.40<\mathrm{V} \leq 0.60)$ & $11,12,13,16,17,22,34,36,40$ & 5 \\
Low $(0.20<\mathrm{V} \leq 0.40)$ & $26,27,32,37,48$ & 10 \\
Very low $(0.00<\mathrm{V} \leq 0.20)$ & $4,6,7,10,18,19,20,44,45,46$ & 0 \\
\hline
\end{tabular}


$(0.755 ; 0.753 ; 0.721 ; 0.612 ; 0.794 ; 0.786 ; 0.727)$; car e $(0.742 ; 0.590 ; 0.869 ; 0.766 ; 0.648 ; 0.681$; $0.861 ; 0.766)$; respect $(0.774 ; 0.655 ; 0.795 ; 0.855$; 0.682; 0.534); learn $\quad(0.861 ; 0.923 ; 0.766$; $0.698 ; 0.850 ; \quad 0.816 ; \quad 0.822 ; 0.915 ; 0.696)$; and contribute $(0.708 ; 0.870 ; 0.846 ; 0.795)$.

The results of this validity test were relevant to the t-test which showed the value of $t$ count $>1.96$, so it can be stated that all QNWL instruments were valid and able to explain the QNWL instrument model. The results of factor analysis with confirmatory factor analysis on each QNWL construct: trust, care, respect, learn, and contribute have met the established goodness of fit criteria. The probability value testing of the goodness of the index indicates a value of 0.996 and the value of RMSEA 0.012. Other model compatibility tests such as AGFI, TLI, and CFI also showed a value of $\geq 0.90$, so it could be stated that existing construct can confirm the theory of QNWL which was the basis for developing instrument.

\section{DISCUSSION}

QNWL is an organizational behaviour variable that gets a lot of attention from practitioners and academics in the field of organizational behaviour. Thus, it needs to be formulated more sharply based on the standard. During this time, the QNWL variable still has various meanings. QNWL is partly defined as matters related to physical welfare or work environment. Meanwhile, there is also a definition stating QNWL as a variable associated with psychological well-being related to job satisfaction and calm at work. This study seeks to define QNWL as an organizational cultural value that creates a work atmosphere which is conducive to psychological wellbeing and nurse performance. QNWL is influenced by internal and external factors.

Internal factor is the environmental condition of nurses that come from individuals and nurse organizations, while the external factor is the condition of the quality of nursing work life that comes from outside the nurse organization. Those factors are divided into three parts, namely patient demand on health system demand, health care policy or health policy, and labour market nursing.

In this study, the instruments of QNWL we used were different from the previous research. The previous research used a theory of Brook and Anderson consisting of 42 items, and it has four subscales (home/work life; work organization/design; work condition/contention; and work world). In this study, dimensions were used according to Riyono (2012) whose assessment was based on psychological aspects. These dimensions consisted of 35 items and five aspects including trust, care, respect, learn, and contribute (Riyono, 2012), while the previous research was more about physical evaluation. This was because this study used a theory stating that QNWL was an organizational culture which was balance-oriented between productivity and employee benefits (subjective wellbeing).
QNWL, in this case, is the employee's perception of the hospital or organization where the nurses work. QNWL is also quite individual because QNWL is how nurses in a hospital or organization assess the hospital or organization in paying attention to their welfare and work productivity. In QNWL, it is applied how hospitals are able to increase the productivity of nurses' work, and the welfare of nurses is also fulfilled at the same time. Thus, there is a balance in QNWL concept between nurse welfare and productivity. This is directly related to job satisfaction since job satisfaction is basically individual and personal, so the things that exist in QNWL concept itself affect employees' job satisfaction. Simply, the higher the QNWL, the higher the job satisfaction of the nurse will be.

Testing of content validity index (CVI) using expert panels was commonly used in the process of organizing instruments as performed by (Salimi and Azimpour, 2013). The content validity index (CVI) in QNWL was between 0.2075 and 0.915 , with very high criteria of $52 \%$ and high criteria of $18 \%$ according to the assessment of 100 experts at the scale of 1-5. In a study conducted by (Sirin, 2015) in Turkish, which used 11 experts in the nursing field, the CVI values were 0.91 with the scale of 1-4.

Instrument reliability (internal consistency) was applied in this study, the intention was that we tested the instrument once only, and then the data obtained from the trial was analyzed using Cronbach $\alpha$ coefficient. This coefficient had a range of $0-1$, which was used to obtain an estimation of internal consistency reliability (Bryne, 2009).

The research results of the reliability test of QNWL instruments using Cronbach alpha was 0.9374 , which was higher than the reliability test of a benchmark (Azwar, 2012) stating that the minimum standard of the test was 0.90 with high takes. Research conducted by Fu Xia, et al, (2015), has Cronbach alpha value of 0,912, and research conducted by Lee Y.W, et al (2014) has Cronbach alpha value of $0.72-0.89$. In conclusion, the QNWL instrument Cronbach $\alpha$ coefficient results are better than those of the previous studies. The test of discrimination power of items in the initial stage used Pearson product moment correlation obtaining a validity score ( $\mathrm{r}$ count) ranged from $0.339-0.79$ for 50 instrument items, then the $r$ table was 0.279 . Thus, the size of the item with $r$ count was bigger than $r$ table meaning that the validity score can be a sufficient reason to state that QNWL instrument was valid. In a study conducted by(Lee et al., 2014), the value of $r=0.72$, which was contrary to a study conducted by Xia $\mathrm{Fu}, \mathrm{Xu}$ Jiajia et al (2015) stating that there were 6 items with a low score in the Pearson product moment correlation and were eventually removed from the model. The final results of testing QNWL instrument showed that there were 35 valid items out of 50 items. Table 2 showed the initial and final drafts for the QNWL instrument.

The construct validity of this research was expected to prove that the measurement results 
obtained through item statement were highly correlated to the theoretical construct of QNWL instrument development. According to Azwar (2012), the validity was conducted through three stages, namely articulating the theoretical concept and the relational principle, developing a way to measure the theoretic hypothetical construct, and empirically testing the hypothetical relationship between the construct and its manifestation, (Devellis, 2012).

This study used factor analysis with confirmatory factor analysis (CFA) to determine the validity of the constraints of QNWL instruments. The aim of CFA was first, to analyze the validity of the instruments, provided that if the load factor $(\lambda)>0.3$ then the instrument was valid; second, to identify the dimensions of the instrument in order to test whether these dimensions were confirmed as well as empirical data truly match. The results of factor analysis with confirmatory factor analysis on each QNWL construct were: trust, care, respect, learn and contribute, of which all results were well. Evaluation of goodness of fit index based on the results of factor analysis showed that the constructs used to form the QNWL model have met the established criteria for goodness of fit index, (Hair, F.H, et al, 2010).

The probability value of testing the goodness of fit index was 0.996, and the value of RMSEA was 0.012 . The other model compatibility tests such as AGFI, TLI, and CFI also showed a value $>0.90$, so that the existing construct on QNWL model could confirm the theory of QNWL, which was the basis for developing the instrument. It was in contrast to a research conducted by Sirin \& Sokmen (2015) in Turkish, showing that the probability value of testing the goodness of fit index was 0.91, and the value of RMSEA is 0.06 . Likewise, a research conducted by $\mathrm{Fu}$ Xia, et al., (2015), showed that the probability value of testing the goodness of fit index was 0.74 , and the value of RMSEA was 0.091 .

\section{CONCLUSION}

Quality of nursing work life instrument in hospitals has fulfilled the criteria of validity and reliability, which include: content validity, item discrimination power, instrument reliability and construct validity. his instrument is recommended to be used to measure the quality of nursing work life by nurses in all hospital classes in Indonesia.

\section{REFERENCES}

Aiken, L. R. (2014). Content Validity and Reliability of Single Items or Questionnaires. Educational and Psychological Measurement, 40(4), 955-959. Https://Doi.Org/10.1177/00131644800400041 9

Almalki, M. J., Fitzgerald, G., \& Clark, M. (2012). Quality of Work Life Among Primary Health Care Nurses in The Jazan Region, Saudi Arabia: A Cross-Sectional Study, 1-13.
Azwar, S. (2012). Reliability dan Validity (4th Ed.). Pustaka Pelajar Yogyakarta.

Bragard, I., Dupuis, G., Razavi, D., Reynaert, C., \& Etienne, A. (2012). Quality of Work Life in Doctors Working with Cancer Patients, (October 2011), 34-40. Doi :10.1093/Occmed/Kqr149

Bryne, B.M, (2009)., Structural Equation Modeling with AMOS Basic Concepts, Applications, and Programming (2 Nd). Taylor and Francis: Group, NY.

Clarke, P. N., \& Brooks, B. (2010). Quality of Nursing Worklife: Conceptual Clarity for The Future, 23(4). Doi : 10.1177/0894318410380268

Devellis, R. F. (2012). Scale Development Second Edition (Second, Vol. 26). Sage Publication.

$\mathrm{Fu}, \mathrm{X}$., Xu, J., Song, L., Li, H., Wang, J., Wu, X., Hu Y., Wei, L., Gao L., Wamh Q., Lin Z., \& Huang H.(2015). Validation of The Chinese Version of The Quality of Nursing Work Life Scale, 605, 1-13. Doi :10.1371/Journal.Pone.0121150

Hair, F.H, William, C.B., Barry, J.B., Rolph, E.A., \& Ronald, L., (2010). Multivariate Data Analysis (Vol. 7 Th).Hamim, N., Suwandi. T., And Yusuf. A. (2015). Caring Behaviour Nurse Based on Quality of Nursing Work Life and Self-Concept in Nursing Nurses in Hospital. International Journal of Development Research, 5(10), 5808-5808.

Kheradman, E, Valilou, M \& Lotfi, A. (2010). The Relation Between Quality of Work Life and Job Performance. Middle East Journal of Scientific Research, 6 No 4, 317-323.

Lee, Y. W., D, P., Dai, Y. T., I. Linda ., Mccreary., Yao G., And Brools B.A.(2014). Psychometric Properties of The Chinese-version Quality of Nursing Work Life Scale, Nursing and Health Sciences, 298-306. Doi : 10.1111/Nhs.12099

Mitchell Ji. (2012). Work Life and Patient Safety Culture in Canadian Healthcare : Connecting The Quality Dot using National Accreditation Results., 15, 51-58.Mohamad, M., \& Mohamed. W.N., (2012). A Model of Quality of Work Life, Life Satisfaction and Service Quality, Asian Journal of Business Research, 2(2), 38-51.

Mosadeghrad, A. M., Ferlie, E., \& Rosenberg, D. (2011). A Study of The Relationship Between Job Satisfaction , Organizational Commitment and Turnover Intention Among Hospital Employees. Doi :10.1258/Hsmr.2011.011009

Nayeri, N. D., Salehi, T., \& Noghabi, A. A. A. (2011). Quality of Work Life (Qwl) and Productivity Among Iranian Nurses. Contemporary Nurse, 39(1), 106-118. Doi :10.5172/Conu.2011.39.1.106

Nursalam, Fardiana A, Asmoro C.P., Fadhilah H., \& Efendi. F. (2018). The Correlation Between The Quality of Nursing Work Life And Job Performance, 9(10). Indian Journal of Public Health Research \& Development. Doi :10.5958/0976-5506.2018.01364.5

Riyono, B., Hartati S., \& Fatdina (2012). Pengembangan Alat Ukur Quality of Work Life. Psikologi Universitas Gadjah Mada. Yogyakarta. 
Salimi And Azimpour. (2013). Journal of Caring Science, 2, 269.

Sirin, M., and Sokmen S.M. (2015). Quality of Nursing Work Life Scale: The Psychometric Evaluation of The Turkish Version. International Journal of Caring Sciences. 8(3), 543-554
Soejadi. (2010). Efisiensi Pengelolaan Rumah Sakit, Grafik Baber Jhonson Sebagai Salah Satu Indikator. Jakarta: Katiga Bina.

Wang, X. (2009). Impact of Depressive Symptoms on The Work-Life Quality of Financial Workers in China. European Psychiatry, 24, S688. Doi :10.1016/S0924-9338(09)70921-6 pp. 93-102). Malden, USA: Blackwell Publishing . 